\title{
Is the Welfare State Sustainable? Experimental Evidence on Citizens' Preferences for Redistribution
}

\author{
Ilja Neustadt ${ }^{1} \&$ Peter $^{2}$ weifel $^{1}$ \\ ${ }^{1}$ University of Zurich, Switzerland \\ Correspondence: Peter Zweifel, Professor emeritus, University of Zurich, Zurich, Switzerland. E-mail: \\ peter.zweifel@uzh.ch
}

Received: March 13, 2015

Accepted: April 6, 2015

Online Published: May 25, 2015

doi:10.5539/ijef.v7n6p60

URL: http://dx.doi.org/10.5539/ijef.v7n6p60

\begin{abstract}
The sustainability of the welfare state ultimately depends on citizens' preferences for income redistribution. The major contribution of this paper is the novel elicitation of these preferences through a Discrete Choice Experiment performed in Switzerland. Attributes of the good are the share of GDP devoted to redistribution, its uses (the unemployed, old-age pensioners, people with ill health etc.), and nationality of beneficiary. Estimated marginal willingness to pay (MWTP) is positive among those who deem current social benefits too low, and negative otherwise. However, even those stating that government should reduce income inequality exhibit a negative MWTP on average. The estimated average WTP is maximum at 21 percent of GDP as of 2008, clearly below and significantly different from the current value of 25 percent. Thus, the Swiss welfare state does not appear sustainable in its present extent.
\end{abstract}

Keywords: income redistribution, welfare state, sustainability, preferences, willingness to pay, discrete choice experiments

\section{Introduction}

The sustainability of the welfare state is a hotly debated topic between politicians and interest groups. The economists' contribution to the debate traditionally has been to analyze the effects of redistributive policies on employment, output, and growth. However, in full cognition of these effects, a majority of citizens may still exhibit willingness to pay (WTP) for more redistribution of income. Conversely, its WTP may be negative even in a situation where these side effects of redistribution are unimportant. Ultimately, the sustainability of the welfare state therefore hinges on citizens' WTP for redistribution. Through a Discrete Choice experiment (DCE), this paper seeks to determine not only the desired amount of redistribution but also to test several hypotheses concerning the determinants of this WTP. The data come from a DCE performed in the fall of 2008 and involving more than 900 Swiss citizens.

Recently, there has been a great deal of research into the demand for redistribution and its determinants, which will be discussed in Section 2 below. One strand relates the measured amount of redistribution to economic, institutional, and behavioral factors. Examples are Alesina and Giuliano (2009) and Akkoyunlu et al. (2009). However, the observed amount of redistribution is the outcome of an interaction between demand and supply, with supply governed by a country's political institutions and processes. This classical identification problem would have to be addressed in order to make inferences about citizens' preferences for redistribution. A second strand of research, exemplified by Alesina and La Ferrara (2005) and Guillaud (2008), relies on surveys designed to measure attitudes towards redistribution. The problem with this approach is its failure to impose a budget constraint. It therefore cannot predict actual decision making (e.g. voting at the polls), where citizens take the consequences in terms of their own income and wealth into account. In the present paper, by way of contrast, an increased amount of income redistribution goes along with a higher share of personal income taxed away. A third approach seeks to solve this problem through Contingent Valuation (CV) studies (see e.g. Boeri et al., 2001; Boeri et al., 2002) (Note 1). The weakness of the CV approach is that it holds all the attributes of the good in question constant, varying its price only. However, one would want to vary other attributes of redistribution besides its tax price, viz. its uses (for health, old age, etc.) and the type of beneficiary (foreigner, national).

By way of contrast, a DCE allows measuring preferences uncontaminated by supply influences, it imposes the budget constraint through the price attribute, and it does so in a realistic way by making respondents choose 
between alternatives where all attributes are allowed to vary. DCEs have been recently applied by Neustadt and Zweifel (2009), Neustadt (2011), and Neustadt and Zweifel (2011) for the case of Switzerland as well as by Pfarr (2013) and Pfarr et al. (2014) for the case of Germany.

There are two contributions whose methodology is similar to the one adopted in this paper. One is by Andreoni and Miller (2002), who test the consistency of altruistic revealed preferences in a dictatorship experiment, varying an implicit price. Their method of inferring preferences through estimating WTP values is close to this paper. The other is by Kuhn (2005), who asked Swiss respondents to estimate wages earned by different professions as well as to indicate the wages they deemed fair. The difference between these two values was then used as an indicator of the demand for redistribution. On average, preferences were for the wages of high-earning professions such as lawyers, physicians, and federal ministers to be reduced by 10 percent while those of low-income groups, to be increased by some 5 percent. Interestingly, such a redistributive scheme would roughly result in budget balance.

The remainder of this paper is structured as follows. Section 2 contains a literature review concerning general determinants of the demand for redistribution from which hypotheses to be tested are derived. Section 3 discusses behavioral determinants of the demand for redistribution with a focus on attitudes towards reduction of inequality. Section 4 presents a general description of the method of DCEs as well as the design of the present experiment. The descriptive statistics of the experiment follow in Section 5, and hypothesis tests, in Section 6. Section 7 summarizes the results and concludes with an assessment of the sustainability of the Swiss welfare state.

\section{Literature Review}

This section first presents research that defines the general background of this paper and then moves on to contributions that lead to a set of specific hypotheses to be tested. In their reviews, Alesina and Giuliano (2009) and Akkoyunlu et al. (2009) identify a wide set of factors that can be categorized as economic, political, and behavioral determinants of the demand for income redistribution. Whilst this section provides a review of the former two sets of factors, behavioral determinants are discussed in Section 3.

The simplest framework for the analysis of purely economic determinants is provided by a model focusing on current economic well-being, originally proposed by Romer (1975) and Roberts (1977) and extended by Meltzer and Richard (1981) (henceforth RRMR model). This model assumes non-altruistic utility-maximizing individuals differentiated by their income levels only. The government pays a lump-sum transfer to all citizens, financed by a linear uniform income tax. Individuals with an income below the mean favor taxation and transfers while those with an income above the mean oppose it. In a political equilibrium, the majority of voters support a positive tax rate corresponding to the value desired by the median voter (Note 2). The model's prediction is that the larger the gap between the mean and the median income, the higher the level of taxation and redistribution.

The empirical evidence is quite mixed. On the one hand, Alesina and Rodrik (1994), Persson and Tabellini (1994), and Milanovic (2000) find some supporting evidence. Furthermore, Guillaud (2008), conducting a cross-section analysis of survey data from four EU countries, shows that poorer and less educated individuals are more in favor of redistribution than richer and more highly educated ones. On the other hand, Alesina and Glaeser (2004), Perotti (1996), and Rodriguez (1999) fail to find supporting evidence for this model. Moreover, Neustadt and Zweifel (2009), relating WTP for income redistribution elicited from a DCE to measures of economic well-being, estimate WTP values to be negatively related to income and education, contradicting the RRMR model.

In Section 6.2 of this paper, we test a modified version of the RRMR model that relates the WTP for redistribution to a subjective measure of economic well-being, equal to one's self-positioning on the income ladder. The WTP values are shown to decrease with this subjective income measure for the lower steps on the ladder and, to increase, for the higher ones. Thus, the RRMR model cannot be confirmed even in its modified form.

Another economic explanation is the "Prospect of Upward Mobility" (POUM) hypothesis, suggested by Hirschman (1973) and dubbed 'tunnel effect'; more recently, it has been reformulated by Benabou and Ok (2001). It extends the RRMR model by introducing individuals' expectations, based on their observations regarding the income mobility of others in society. Expected upward mobility may dampen a poor but forward-looking voter's enthusiasm for income redistribution.

Empirical support of the POUM hypothesis is provided by Alesina and La Ferrara (2005) who, using an actual mobility matrix for the United States, show that people who can expect high future income do oppose 
redistribution (Note 3). Rainer and Siedler (2008) employ probabilistic expectations data to show that individuals with a sufficiently large chance of occupational upward mobility exhibit a lower demand for redistribution; conversely, those with a sufficiently large risk of occupational downward mobility opt for more redistribution. Checchi and Filippin (2004), testing the POUM hypothesis by means of a within-subjects experiment, find corroborating evidence under several alternative specifications. According to Guillaud (2008), however, individuals who subjectively experienced upward mobility over ten years tend to be more (rather than less) supportive of redistributive policies. Moreover, upward intergenerational mobility in occupational prestige goes along with more positive rather than negative attitude towards redistribution. Alesina and Giuliano (2009) examine the empirical evidence for the United States and briefly across countries, concluding that social mobility (measured as the change in the occupational prestige) does decrease demand for redistribution once sociodemographic (age, gender, race) and socioeconomic characteristics (income, education) are controlled for. In their DCE-based study, Neustadt and Zweifel (2009) relate preferences for redistribution to mobility. They find partial empirical support for the POUM hypothesis.

Another economic explanation, suggested by the social contract literature, is that preferences for redistribution can at least in part be interpreted as a demand for insurance by risk-averse individuals. In a hypothetical situation, where individuals do not yet know their endowment as well as their future position in society ('veil of ignorance', cf. Rawls, 1999), they are predicted to exhibit positive WTP for an income transfer from more favorable future states to less favorable ones. Redistributive policies can thus be interpreted as reflecting this hypothetical demand for insurance. Beck (1994) investigates individual behavior under the 'veil of ignorance' in an experiment. By placing participants in a hypothetical society with random differences in income, represented by lotteries, he is able to derive the desired amount of income redistribution. Individuals indeed display risk aversion, albeit not of the extreme kind implied by the Rawlsian maximin rule (Note 4). Furthermore, they show no preference for income redistribution in excess of what can be explained by risk aversion.

As to the political determinants of the demand for income redistribution, the literature (Persson \& Tabellini, 2000, 2003; Lizzeri \& Persico, 2001; Milesi-Ferretti et al., 2002) predicts that proportional representation tends towards universal programs benefitting various groups (old-age pensioners, working poor, minorities, etc.), while majority rule results in targeted 'pork barrel' programs. Persson and Tabellini (2003) find supporting empirical evidence in that countries with proportional representation have GDP shares of government expenditure that ceteris paribus are 5 percentage points higher than countries with majority rule. Moreover, Akkoyunlu et al. (2009) present weak evidence of a positive correlation between the degree of proportional representation and the transfer share in GDP in OECD countries. Additional political determinants of redistribution include two-party vs. multiparty system, presidential vs. parliamentary democracy, and direct vs. representative democracy, with two-party systems, presidential, and direct democracies all predicted to induce less public redistribution. Since the present study is a DCE involving participants from one country only, it cannot test for the influence of these factors. Still, it is appropriate to provide some institutional background describing Switzerland along the dimensions cited. Switzerland with a population of 7.7 million people at the time of the DCE is characterized by (see e.g. Kriesi \& Trechsel, 2008; Chapters 4 and 6).

- proportional representation rather than majority rule at the federal level and most member states (cantons);

- a multiparty system at both the federal and the cantonal level;

- extensive direct democratic control in the guise of popular initiatives and referenda.

\section{Behavioral Determinants of Demand for Redistribution and Statement of Hypotheses}

The mixed empirical evidence bearing on the economic determinants of preferences for redistribution calls for a detailed analysis of their behavioral determinants. One set relates to beliefs in luck or effort. The theoretical base is laid by Alesina and Angeletos (2005), who develop a model where society's belief whether effort or luck determines economic success gives rise to multiple equilibria with self-fulfilling predictions. Benabou and Tirole (2006) propose a model for the emergence and persistence of such collective beliefs. Depending on type, they can be seen as a source of altruistic preferences and inequality aversion. Fong (2001) presents evidence in line with Alesina and La Ferrara (2005) suggesting that beliefs about the role of luck in determining economic success are an important determinant of the demand for redistribution. She also considers the effects of incentives. If effort determines income, then an increased income tax rate causes an output loss due to its effect on incentives. This consideration is hypothesized to qualify the link between beliefs and the demand for redistribution. However, her data fail to support this hypothesis.

Neustadt (2011) uses Swiss data and shows that the estimated marginal WTP for income redistribution is positive among respondents who do not belong to a religious denomination, and negative otherwise, becoming more 
marked with a higher degree of religiosity. Moreover, respondents who state that luck plays a decisive role in determining economic success exhibit significantly higher WTP values than those who deem effort to be decisive.

A second set of behavioral determinants is related to attitudes towards reduction of inequality based on interpersonal trust. Using data from Russia, Borisova et al. (2014) investigate the relationship between interpersonal trust and preferences for redistribution to different groups of recipients, confirming the hypothesis that people prefer less redistribution from the rich to the poor in an environment with a greater level of interpersonal trust. The estimated impact of trust on views on inequality is twice as large as that of female gender, and close to the (negative) effect of social expenditure in the particular region.

A third set of behavioral determinants has to do with attitudes towards reduction of inequality based on relative income. Taking the RRMR model as the benchmark, a higher amount of income redistribution is desired and hence sustainable if inequality aversion prevails, while the POUM hypothesis predicts the opposite, i.e. a lower sustainable amount of redistribution. Fehr and Schmidt (2006) provide a review of several models of social preferences, in particular, altruism, envy, inequality aversion, fairness, and reciprocity. Here, we focus on inequality aversion to derive hypotheses relating it to demand for income redistribution. In a simple model of inequality aversion, Fehr and Schmidt (1999) assume that individuals feel envy if their incomes are below that of others ('disadvantageous inequality', see second term of eq. (1)), but they feel altruistic when their income exceeds it ('advantageous inequality', see third term of eq. (1)). They posit a utility function for individual $i$ of the form

$$
U_{i}\left(x_{1}, \ldots, x_{n}\right)=x_{i}-\frac{\alpha_{i}}{N-1} \sum_{j \neq i} \max \left\{x_{j}-x_{i}, 0\right\}-\frac{\beta_{i}}{N-1} \sum_{j \neq i} \max \left\{x_{i}-x_{j}, 0\right\} .
$$

where $x_{k}, k=1, \ldots, N$, denotes individual $k$ 's income, $\alpha_{i}$, the marginal disutility from disadvantageous inequality, and $\beta_{i}$, the marginal disutility from advantageous inequality. It is assumed that $0 \leq \beta_{i} \leq \alpha_{i}$ (the disutility from disadvantageous inequality is assumed to exceed that from advantageous inequality) and $\beta_{i} \leq 1$ (individuals are not willing to waste money in order to avoid being significantly richer than others). In this model, the decisive median voter demands more redistribution than in the conventional RRMR model. First, she has disutility from being richer than those with income $x_{j}<x_{i}$. Second, she has even more disutility from being poorer than those with income $x_{j}>x_{i}$. Thus in a political equilibrium, larger values of $\alpha_{i}, \beta_{i}$ (higher level of inequality aversion) lead to a higher demand for redistribution compared to that predicted by the RRMR model.

Since the DCE of this paper revolves around redistribution, inequality aversion is related to social benefits and government activity designed to reduce the income gap between rich and poor rather than the income distribution resulting from factor markets. One approach is backward-looking, measuring inequality aversion by asking respondents whether they deem the current level of social benefits to be too low, just sufficient, or too high. It leads to

Hypothesis 1: Marginal willingness to pay for redistribution is expected to be:

(A) negative if the currently provided level of social benefits is considered too high.

(B) negative but less so than in (A) if the currently provided level of social benefits is considered to be just sufficient.

(C) positive if the currently provided level of social benefits is considered too low.

Alternatively, the approach can be forward-looking and normative, measuring inequality aversion by having respondents evaluate government activity. Here, respondents who state that the government should do more to reduce the income gap are expected to exhibit a positive MWTP for redistribution.

Hypothesis 2: Marginal willingness to pay for redistribution is expected to be:

(a) negative if the individual thinks that the government should not reduce the income gap between the poor and the rich.

(b) positive if the individual thinks that the government should reduce the income gap between the poor and the rich.

Note that while these two hypotheses may appear to be almost self-evident, they cannot be derived from either the RRMR or the POUM models, both of which are couched in terms of strictly individualistic preferences.

\section{The Discrete Choice Experiment}

\subsection{Theoretical Foundations}

Discrete Choice Experiments (DCEs) provide a tool for measuring individuals' preferences for characteristics of 
commodities, the so-called attributes. In contradistinction to classical Revealed Preference Theory, originating with Samuelson (1938), DCEs allow individuals to express their preferences for non-marketed as well as hypothetical products. During a DCE, respondents are repeatedly asked to compare the status quo with several hypothetical alternatives defined by their attributes including a price. By varying the levels of attributes, different product alternatives are generated. Assuming that rational individuals always choose the alternative with highest utility, the researcher can infer the utility associated with the attributes from the observed choices. The proposed method, derived from the New Demand Theory of Lancaster (1971), is also known as Conjoint Analysis (Louviere, 2000).

The most prominent alternative to a DCE is Contingent Valuation (CV). A certain situation or product is described in detail, and respondents are asked to indicate their maximum WTP for this fixed product. Only its price attribute is varied, while in Conjoint Analysis all relevant attributes are varied simultaneously, making it a multi-attribute valuation method (Merino-Castello, 2003). A DCE describes the product in less detail than a typical CV study; in return, it allows for analyzing many product varieties by varying the levels of relevant attributes (Louviere, 2000, p. 344). Trade-offs among attributes can be explicitly taken into account and WTP values of attributes estimated separately (see below). Furthermore, strategic behavior of respondents is less likely than in CV with its exclusive emphasis on price, which facilitates strategic behavior. Finally, biases that easily occur when individuals are directly asked about their WTP are less frequently observed in DCEs (Ryan, 2004).

A particular advantage of a DCE in the present context is that it permits to explicitly impose the budget constraint through a price attribute in the guise of the tax share of income used to finance the transfers considered. Respondents can be made to simultaneously choose this share and hence the 'size of the pie' and the 'slices of the pie' devoted to different types of recipients and uses (health, old age, etc.; see Exhibits B1 to B3 in Appendix B). Thus, trade-offs among different attributes of redistribution can be calculated to assess the relative importance of the respective redistributive goals.

The econometric method used is based on Random Utility Theory (Luce, 1959; Manski \& Lerman, 1977; McFadden, 1974, 1981, 2001; see Appendix 1 for details).

A simple model relating utilities and choice probabilities to attributes only (see Section 4.1 below), the deterministic part of the indirect utility function is postulated to be

$$
w_{i}\left(a_{j}, p_{j}, y_{i}, s_{i}\right)=c_{i}+\sum_{k=1}^{K} \beta_{k} a_{k j}+\varepsilon_{i j},
$$

where $c_{i}$ represents an individual-specific constant, $a_{k}, k=1, \ldots, K$, are the attributes of the alternative, and $\beta_{k}, k=1, \ldots, K$, are the parameters to be estimated. These parameters can be interpreted as the constant marginal utilities of the corresponding attributes. One obtains the following expression representing the difference in utility of individual $i$ between alternative $j$ and status quo,

$$
\Delta V_{i j}=c_{i}+\sum_{k=1}^{K} \beta_{k} \Delta a_{k j}+\beta_{p} \Delta p_{j}+\varphi_{i j},
$$

where $\Delta a_{k j}=a_{k j}-a_{l j}, \Delta p_{j}=p_{j}-p_{l}, c_{i}=c_{i l}-c_{i j}$, and $\varphi_{i j}=\varepsilon_{i l}-\varepsilon_{i j}$ for each $j \neq l$. The marginal rate of substitution between two attributes $m$ and $n$ is given by

$$
M R S_{m, n}=-\frac{\partial \Delta V / \partial \Delta a_{m}}{\partial \Delta V / \partial \Delta a_{n}} .
$$

Therefore, the marginal WTP for attribute $a_{m}$ can be calculated by dividing the marginal utility of this attribute by the marginal utility of the price attribute (in the present context, the income tax rate, see e.g. Telser (2002), p.56] (Note 5):

$$
\operatorname{MWTP}\left(a_{m}\right)=\frac{\partial \Delta V / \partial \Delta a_{m}}{\partial \Delta V / \partial \Delta p_{j}} .
$$

For econometric inference, it is important to recall that the same individual makes several choices. The two-way random-effect specification takes this into account through $\varphi_{i j}=\mu_{i}+\eta_{i j}$ where $\mu_{i}$ denotes the component that varies only across individuals but not across the choice alternatives. The terms $\mu_{i}$ and $\eta_{i j}$ are assumed uncorrelated with the product attributes $\left(a_{i 1}, \ldots, a_{i K}\right)$ and between themselves. By a standard assumption in probit models, $\sigma_{\eta}=1$. Hence $\operatorname{Var}\left[\varphi_{i j}\right]=\sigma_{\eta}^{2}+\sigma_{\mu}^{2}=1+\sigma_{\mu}^{2}$ and $\operatorname{Corr}\left[\varphi_{i j}, \varphi_{i l}\right]=\sigma_{\mu}^{2} /\left(1+\sigma_{\mu}^{2}\right)=: \rho$. The parameter $\rho$ indicates how strongly the various responses of an individual are correlated with each other, or, equivalently, the share of the total variance that can be explained by the individual-specific error term. The random-effects specification is justified if $\rho$ is high and significant.

\subsection{Experimental Design}

The experiment was conducted with a representative sample of 979 respondents in the fall of 2008 . Respondents 
were provided with full decision sets including graphical representations of the status quo and alternatives (see Appendix B for examples) and were asked to submit their binary choices during a telephone survey. In order to make sure that decisions were based on a homogeneous information set and made in a consistent way, respondents additionally received a detailed description of the attributes and their possible realizations. Appendix B shows the graphical representation of the status quo (Exhibit B1) and two selected alternatives (Exhibits B2 and B3). Data collection followed in a telephone survey some days later and additionally included a questionnaire covering a wide range of respondents' socioeconomic and behavioral characteristics.

Table 1. Attributes and their levels

\begin{tabular}{|c|c|c|c|}
\hline Attribute & Label & Status Quo Level & Alternative Levels \\
\hline \multicolumn{4}{|l|}{ Shares of benefits going to } \\
\hline - Working poor & W_POOR & $10 \%$ & $5 \%, 15 \%$ \\
\hline - $\quad$ Unemployed & UNEMP & $15 \%$ & $5 \%, 25 \%$ \\
\hline - $\quad$ Old-age pensioners & PENS & $45 \%$ & $35 \%, 55 \%$ \\
\hline - $\quad$ Families with children & FAM & $5 \%$ & $10 \%$ \\
\hline - $\quad$ People with ill health & ILL & $25 \%$ & $20 \%, 30 \%$ \\
\hline \multicolumn{4}{|l|}{ Shares of benefits going to } \\
\hline - $\quad$ Swiss citizens & SWISS & $75 \%$ & $60 \%, 85 \%$ \\
\hline - Western European citizens & WEU_FOR & $10 \%$ & $5 \%, 20 \%$ \\
\hline - $\quad$ Other foreigners & OTH_FOR & $15 \%$ & $10 \%, 20 \%$ \\
\hline Total amount of redistribution & REDIST & $25 \%$ (of GDP) & $10 \%, 20 \%, 30 \%, 40 \%, 50 \%$ \\
\hline Income tax & TAX & $25 \%$ (of personal income) & $10 \%, 15 \%, 40 \%$ \\
\hline
\end{tabular}

Prior to the experiment, the attributes and their levels used to define 'income redistribution' had been checked in two pretests for their relevance. There are four types of attributes (see Table 1 and Appendix B),

1) Shares of the total redistribution budget to be spent on five types of recipients (viz. the working poor, the unemployed, old-age pensioners, families with children, and people with ill health);

2) Shares of the total redistribution budget to be spent on three groups (viz. Swiss citizens, western European foreigners, and other foreigners);

3) Total amount of redistribution, defined as a share of GDP;

4) Personal income tax rate to be paid by the respondent (the price attribute).

These attributes and their levels combine to form a total number of possible scenarios that is excessive for an experiment. The scenarios define the $n$ rows of the observation matrix $X$, with associated covariance matrix $\Omega=\sigma^{2}\left(X^{\prime} X\right)^{-1}$ of parameters $\beta$ to be estimated. So-called $D$-efficient design calls for the minimization of the geometric mean of the eigenvalues of $\Omega$,

$$
D \text {-efficiency }=\left(|\Omega|^{\frac{1}{K}}\right)^{-1}
$$

where $K$ denotes the number of parameters to be estimated [Carlsson \& Martinsson (2003)] (Note 6). Using this optimization procedure and incorporating several restrictions, the number of alternatives was reduced to 35 and randomly split into five groups. One alternative was included twice in each decision set for a consistency test, resulting in eight binary choices per respondent.

\section{Descriptive Statistics}

\subsection{Socioeconomic Characteristics}

The sample consists of 979 respondents, 70 percent of them residing in the German-speaking part and 30 percent in the French-speaking part of Switzerland. Some 94 percent are born in the country, 50 percent are men, 20 percent having monthly incomes below CHF 2,000 and 23 percent, above CHF 6,000, reflecting the structure of the Swiss population. However, only 1.5 percent of the respondents are unemployed. The survey was implemented by an organization that specializes in nationally representative surveys using a carefully developed sampling strategy. 
Table 2. Answers to the question, "Do you think that the government is spending too much, too little or about the right amount on welfare?” by income group

\begin{tabular}{lllllllllc}
\hline & \multicolumn{2}{l}{ too little } & \multicolumn{2}{l}{ right amount } & \multicolumn{2}{l}{ too much } & total valid answers & missing \\
\hline Income group, CHF & No. & $\%$ & No. & $\%$ & No. & $\%$ & No. & $\%$ & No. \\
\hline$<$ CHF 2000 & 63 & 35 & 100 & 56 & 16 & 9 & 179 & 100 & 13 \\
CHF 2000-3999 & 58 & 32 & 94 & 53 & 27 & 15 & 179 & 100 & 14 \\
CHF 4000-5999 & 141 & 43 & 149 & 45 & 39 & 12 & 329 & 100 & 15 \\
$>$ CHF 6000 & 79 & 37 & 118 & 56 & 14 & 7 & 211 & 100 & 10 \\
\hline Missing & 11 & & 16 & & 1 & & 28 & & \\
\hline Total answers & 352 & 38 & 477 & 52 & 97 & 10 & 926 & & 53 \\
\hline
\end{tabular}

Note. CHF (Swiss franc) $=0.8$ US\$ at 2008 exchange rates.

Some 38 percent of the respondents stated that the current level of social benefits was too low, 10 percent stated that it was too high, and 52 percent found it exactly right (see Table 2). On the other hand, 45 percent agreed with the statement, "By increasing the income tax rates for rich families and financially supporting poor families, the government should try to reduce the income gap between the rich and the poor", while 55 percent disagreed (see Table 3).

Table 3. Answers to the question, "Do you agree with the following statement: 'By increasing the income tax rates for rich families and financially supporting poor families, the government should try to reduce the income gap between the rich and the poor'?" by income group

\begin{tabular}{lllllllc}
\hline & \multicolumn{2}{c}{ yes } & \multicolumn{2}{l}{ no } & & total valid answers & missing \\
\hline Income group, CHF & No. & $\%$ & No. & $\%$ & No. & $\%$ & No. \\
\hline$<$ CHF 2000 & 78 & 42 & 108 & 58 & 186 & 100 & 6 \\
CHF 2000 - 3999 & 112 & 59 & 77 & 41 & 189 & 100 & 4 \\
CHF 4000 - 5999 & 124 & 37 & 212 & 63 & 336 & 100 & 8 \\
$>$ CHF 6000 & 90 & 42 & 122 & 58 & 212 & 100 & 9 \\
Missing & 13 & & 16 & & 29 & & \\
Total answers & 417 & 45 & 535 & 55 & 952 & & 27 \\
\hline
\end{tabular}

Note. CHF (Swiss franc) $=0.8$ US\$ at 2008 exchange rates.

The distribution of answers over income groups obviously contradicts the RRMR model. For instance, 35 percent of respondents with monthly incomes below CHF 2,000 (the 'poor') deem the current amount of social benefits too low, but this holds true for even 37 percent of those with incomes above CHF 6,000 (the 'rich') (see Table 2 again). Similarly, the percentage of those finding the current size of the welfare state excessive is 9 percent among the 'poor' but only 7 percent among the 'rich'. Moreover, the share of those supporting a reduction of the income gap by public redistribution is 42 percent both among the 'rich' and the 'poor' (see Table $3)$.

Table 4. Answers to the question, "What is your self-assessed position on the income ladder from step 1 (the poorest ones) to step 10 (the richest ones)?" by income group

\begin{tabular}{lllllllllllc}
\hline & steps 1 to 3 & step 4 & \multicolumn{3}{c}{ step 5 } & \multicolumn{2}{c}{ steps 6 to 9 } & total valid answers & missing \\
\hline Income group, CHF & No. & $\%$ & No. & $\%$ & No. & $\%$ & No. & $\%$ & No. & $\%$ & No. \\
\hline$<$ CHF 2000 & 46 & 24 & 79 & 39 & 56 & 29 & 10 & 5 & 191 & 100 & 1 \\
CHF 2000 - 3999 & 69 & 36 & 71 & 37 & 41 & 21 & 12 & 6 & 193 & 100 & 0 \\
CHF 4000 - 5999 & 61 & 18 & 177 & 52 & 82 & 24 & 22 & 6 & 342 & 100 & 2 \\
$>$ CHF 6000 & 20 & 9 & 72 & 33 & 79 & 36 & 50 & 23 & 221 & 100 & 0 \\
Missing & 5 & & 6 & & 12 & & 4 & & 27 & 2 \\
Total answers & 201 & 21 & 405 & 42 & 270 & 28 & 98 & 10 & 974 & 5 \\
\hline
\end{tabular}

Note. CHF (Swiss franc) $=0.8$ US\$ at 2008 exchange rates. 
However, it is essential to distinguish between the objective current income level and the subjective beliefs of the respondents concerning their relative income status. For example, those respondents who belong to a high income group may not think they are 'rich'. Table 4 supports this assertion, showing the correlation between the income levels and subjective socioeconomic status. Whereas 34 percent of respondents from the lowest income group think they belong to at least Step 5 of the income ladder, making them relatively 'rich', 42 percent of respondents from the highest income group think to be relatively 'poor' by placing themselves on Steps 1 to 4 . With a rather low correlation coefficient of 0.26 , the relationship between objective and subjective socioeconomic status suggests that it is more appropriate to relate inequality aversion to subjective beliefs regarding one's income rather than objective measures of income.

Table 5. Answers to the question, "Do you think that the government is spending too much, too little, or about the right amount on welfare?" by self-assessed position on the income ladder

\begin{tabular}{lllllllllc}
\hline & \multicolumn{2}{l}{ too little } & \multicolumn{2}{l}{ right amount } & \multicolumn{2}{l}{ too much } & \multicolumn{2}{c}{ total valid answers } & missing \\
\hline Self-assessed economic status & No. & $\%$ & No. & $\%$ & No. & $\%$ & No. & $\%$ & No. \\
\hline Steps 1 - 3 & 64 & 34 & 86 & 46 & 37 & 20 & 187 & 100 & 14 \\
Step 4 & 163 & 42 & 192 & 49 & 35 & 9 & 390 & 100 & 15 \\
Step 5 & 93 & 37 & 140 & 56 & 18 & 7 & 251 & 100 & 19 \\
Steps 6 - & 31 & 33 & 56 & 60 & 7 & 7 & 94 & 100 & 4 \\
Missing & 1 & & 3 & & 0 & & 4 & & 1 \\
Total answers & 352 & 38 & 477 & 52 & 97 & 10 & 926 & & 43 \\
\hline
\end{tabular}

Table 5 only partially confirms this assertion, showing that share of the status quo supporters among all respondents (column 'right amount', \%) increases with self-assessed social status. However, share of those who support the reduction of the income gap between the rich and the poor by public redistribution is maximum (57\%) among the respondents with highest self-assessed economic status while maximum opposition to the reduction of income gap (67\%) prevails among those who deem themselves moderately poor (Step 4) (see Table 6). Therefore, the contradictions presented in Tables 2 and 3 are unlikely to be explained by failure of the rich to feel rich and the poor, to feel poor.

Table 6. Answers to the question, "Do you agree with the following statement: 'By increasing the income tax rates for rich families and financially supporting poor families, the government should try to reduce the income gap between the rich and the poor'?" by self-assessed position on the income ladder

\begin{tabular}{lllllllc}
\hline & yes & \multicolumn{3}{c}{ no } & & total valid answers & missing \\
\hline Self-assessed economic status & No. & $\%$ & No. & $\%$ & No. & $\%$ & No. \\
\hline Steps 1 - 3 & 97 & 50 & 97 & 50 & 194 & 100 & 7 \\
Step 4 & 133 & 33 & 265 & 67 & 398 & 100 & 7 \\
Step 5 & 131 & 50.4 & 129 & 49.6 & 260 & 100 & 10 \\
Steps 6 - & 55 & 57 & 41 & 43 & 96 & 100 & 2 \\
Missing & 1 & & 3 & & 1 & & \\
Total answers & 417 & 45 & 535 & 55 & 948 & & 27 \\
\hline
\end{tabular}

These findings motivate examining explanations of the demand for income redistribution based on beliefs and inequality aversion. However, as noted in Section 3, inequality aversion could be due to risk aversion in front of the 'veil of ignorance'. Indeed, 56 percent of respondents state 'insurance' as their main motive for redistribution, compared to 44 percent citing 'inequality reduction' (see Table 7). Attitudes clearly differ between the two groups, too. Only one-third of respondents with the 'insurance' motivation support the idea of inequality reduction to be brought about by government, compared to 55 percent of those with the 'inequality reduction' motive. In sum, 'true' inequality aversion in the sense of Fehr and Schmidt (1999) may well be relevant, at least in the present sample. 
Table 7. Answers to the questions, "Do you agree with the following statement: 'By increasing the income tax rates for rich families and financially supporting poor families, the government should try to reduce the income gap between the rich and the poor'?" and "What is your main motive for redistribution: insurance or inequality reduction?"

\begin{tabular}{lllllllc}
\hline & yes & & no & & \multicolumn{2}{c}{ total valid answers } & missing \\
\hline Redistribution motive & No. & $\%$ & No. & $\%$ & No. & $\%$ & No. \\
\hline Insurance & 164 & 33 & 339 & 67 & 503 & 100 & 10 \\
Inequality reduction & 219 & 55 & 181 & 45 & 400 & 100 & 13 \\
Missing & 34 & & 15 & & 49 & & \\
Total answers & 417 & 45 & 535 & 55 & 952 & & 27 \\
\hline
\end{tabular}

\subsection{Respondents' Choice Behavior}

Table 8. Total number of choices

\begin{tabular}{lll}
\hline Choices & No. & in percent \\
\hline Alternative & 1,562 & 19.94 \\
Status quo & 6,088 & 77.73 \\
No decision & 182 & 2.32 \\
Total & 7,832 & 100 \\
\hline
\end{tabular}

There is a total of $979 \cdot 8=7,832$ choices, of which almost 20 percent were made in favor of an alternative over the status quo (see Table 8). There are at least three explanations for this low percentage. First, in spite of checking in the pretests, the levels of the attributes in the experiment might not have been sufficiently spaced apart to make respondents switch. Second, some attributes (e.g. benefits going to the unemployed; see Table 10), might not have been important enough to cause a switch. Finally, there may be errors in decision making because a test (presenting the same choice twice) revealed 14 percent of choices to be inconsistent. However, there may be simply a marked status quo bias in the face of highly complex decision-making situations, as suggested by the large negative constant in Table 10. Nonetheless, only 21 percent of respondents never opted for an alternative [see Table 8 again), implying that almost 80 percent departed from the status quo at least once. No more than 11 percent of respondents stated that the DCE was difficult or very difficult, a figure in the usual range (see e.g. Telser, 2002, Ch. 4, who reports a share of 28 percent).

Table 9. Distribution of the number of chosen alternatives per respondent

\begin{tabular}{lcc}
\hline \# choices for alternative & No. & in percent \\
\hline 0 & 209 & 21.35 \\
1 & 309 & 31.56 \\
2 & 226 & 23.08 \\
3 & 131 & 13.38 \\
4 & 57 & 5.82 \\
5 & 16 & 1.63 \\
6 & 10 & 1.02 \\
7 & 0 & 0.00 \\
8 & 5 & 0.51 \\
\hline Total valid answers & 965 & 98.57 \\
Missing & 14 & 1.43 \\
Sample & 979 & 100 \\
\hline
\end{tabular}

\section{Estimation}

\subsection{Simple Model: Product Attrubutes Only}

Estimation of equation (3) includes the quadratic term REDIST ${ }^{2}$ to allow for possible non-linearity of the indirect utility function (predicated by risk aversion and the insurance motive for redistribution, see Section 3 ) with regard to the GDP share of redistribution REDIST. Moreover, the fact that uses and types of beneficiaries add up 
to 100 percent needs to be taken into account (see Table 1). In order to avoid perfect collinearity, PENS (Pensioners) and $\mathrm{OTH}_{-}$FOR (Other foreigners) were dropped to obtain the specification (see Table 1 for variable definitions)

$$
\begin{gathered}
\Delta V=c_{0}+\beta_{1} \Delta W_{P O O R}+\beta_{2} \Delta U N E M P+\beta_{3} \Delta I L L+\beta_{4} \Delta F A M+ \\
+\gamma_{1} \Delta S W I S S+\gamma_{2} \Delta W E U_{-} F O R+\delta_{1} \Delta R E D I S T+\delta_{2} \Delta R E D I S T^{2}+\eta \Delta T A X+\varphi
\end{gathered}
$$

Estimation of a subset of the $5 \times 3=15$ specifications with alternative exclusions produced results similar to those displayed in Table 10. Specifically, they agree in that alternatives with additional redistribution are chosen with a lower probability (for details with regard to 'slices' of the pie, see Neustadt \& Zweifel, 2011). Also, note the sizeable and highly significant coefficient of the price attribute $T A X$, which is important for the estimation of MWTP values (see eq. (5)). The MWTP value for redistribution is given by

$$
M W T P_{R E D I S T}=\frac{\partial \Delta V / \partial \Delta R E D I S T}{\partial \Delta V / \partial \Delta T A X}=-\frac{\delta_{1}+2 \delta_{2} R E D I S T}{\eta}
$$

According to Table 10, this amounts to -0.25 percentage points of income share per additional percentage point of GDP devoted to redistribution in excess of the status quo. Evaluated at the mean personal income of the sample, this equals CHF - 11.78 per month. However, this figure is dwarfed by the compensation one would have to pay respondents to depart from the status quo, amounting to an estimated 63 percent of their monthly income, or 5.27 percent of their annual income (see the large negative constant in Table 10).

Table 10. Random effects probit estimates of the simple model

\begin{tabular}{lllllc}
\hline Variable & Coefficient & Standard error & $z$ & $p$-value & Marginal effect \\
\hline Recipient's social group & & & & & \\
W_POOR & 0.02784 & 0.00714 & 3.90 & 0.000 & 0.00697 \\
UNEMP & 0.01134 & 0.00452 & 2.51 & 0.012 & 0.00284 \\
ILL & 0.01600 & 0.00463 & 3.46 & 0.001 & 0.00400 \\
FAM & 0.06378 & 0.00942 & 6.77 & 0.000 & 0.01596 \\
\hline Recipient's nationality & & & & & \\
SWISS & 0.03656 & 0.00552 & 6.63 & 0.000 & 0.00915 \\
WEU_FOR & 0.02925 & 0.00869 & 3.37 & 0.001 & 0.00732 \\
\hline REDIST & -0.00523 & 0.00176 & -2.97 & 0.003 & -0.00131 \\
REDIST^2 & -0.06619 & 0.01174 & -5.64 & 0.000 & -0.01656 \\
TAX & -0.02053 & 0.00183 & -11.21 & 0.000 & -0.00514 \\
Constant & -1.29878 & 0.06132 & -21.18 & 0.000 & n.a. \\
\hline
\end{tabular}

Where: \# observations: 7,650; $\log$ likelihood: $-3,566.76 ; \chi^{2}(0): 108.87 ;$ Prob $>\chi^{2}: 0.000 ; \sigma_{u}: 0.41610 ; \rho: 0.14759$.

Equation (7) serves as the basis for checking the sustainability of the welfare state. Construction of the (quadratic) WTP function yields a maximum (with MWTP=0) at 21.05 percent of GDP, definitely below the current value of 25 percent. Therefore, the Swiss welfare state can be said to be too big in the light of citizens' mean preferences.

\subsection{Extended Model: Preference Heterogeneity}

\subsubsection{Subjective Beliefs about Income Status and Preferences for Redistribution}

Here, the simple model is extended by including the self-positioning on an income ladder as well as its interactions with the attributes. The four groups of respondents are represented by three dummy variables, STEP1-3, STEP5 and STEP6-9. For instance, the dummy variable STEP6-9 is set to be equal to 1 if the respondent belongs to steps $6,7,8$ or 9 on the income ladder, or equal to zero otherwise. The reference category is STEP4, indicating that the respondent believes that he belongs to step 4 on the income ladder. Since an attribute's marginal utility may vary with attitude, eg. (6) is modified to contain interaction terms involving the attitudinal variables, resulting in

$$
\begin{aligned}
& \Delta V^{\prime}=c_{0}^{\prime}+\cdots+\alpha_{1}^{\prime} S T E P 1-3+\alpha_{2}^{\prime} S T E P 5+\alpha_{3}^{\prime} S T E P 6-9+\alpha_{4}^{\prime} \Delta R E D I S T+\alpha_{5}^{\prime} \Delta R E D I S T^{2}+\ldots \\
& +\lambda_{2}^{\prime} \Delta R E D I S T \cdot S T E P 1-3+\lambda_{3}^{\prime} \Delta R E D I S T^{2} \cdot S T E P 1-3+\ldots \\
& +\lambda_{4}^{\prime} \triangle R E D I S T \cdot S T E P 5+\lambda_{5}^{\prime} \Delta R E D I S T^{2} \cdot S T E P 5+\ldots \\
& +\lambda_{6}^{\prime} \Delta R E D I S T \cdot S T E P 6-9+\lambda_{7}^{\prime} \Delta R_{E D I S T}^{2} \cdot S T E P 6-9+\cdots+\varphi^{\prime} \text {. }
\end{aligned}
$$


As opposed to the classical RRMR model that lacks empirical support, there is partial evidence concerning the effects of subjective beliefs about income status on MWTP for redistribution. As shown in Table 11, which summarizes MWTP values for different groups of respondents, resistance against redistribution seems to increase from the lowest to group No. 2 of the subjective income ladder. Yet, the difference between Groups 1 and 2 is not significant $(t=-1.20)$. However, MWTP for redistribution increases from group No. 2 (whichincludes the median respondent) to the highest. Therefore, the contradictions in Tables 2 and 3 (see Section 5.1) cannot be explained by failure of the rich to feel rich and the poor, to feel poor.

Table 11. Marginal WTP values for redistribution (in percent of monthly personal income and CHF) derived from the model extended to include the subjective belief about the position on the income ladder

\begin{tabular}{llll}
\hline Variable & MWTP, \% of income & MWTP, CHF & Standard error, CHF \\
\hline Social group 1 (steps 1 to 3) & -0.40762 & -14.72 & $8.49^{* * *}$ \\
Social group 2 (step 4) & -0.65405 & -28.45 & $8.81^{* * *}$ \\
Social group 3 (step 5) & -0.30303 & -15.06 & $12.36^{*}$ \\
Social group 4 (steps 6 to 9) & 0.25550 & 17.61 & $11.01^{*}$ \\
\hline
\end{tabular}

Note. $* * *(* *, *)$ denotes statistical significance at the $1(5,10)$ percent level.

\subsubsection{Ex-Post Evaluation of the Current Level of Social Benefits and Preferences for Redistribution}

The simple model is now extended by one attitudinal variable at a time. The first is respondents' ex-post evaluation of the current level of social benefits (SB, see Table 2). The three levels of SB are represented by two dummy variables, $S B \_T O O H I$ and $S B \_T O O L O W$. For instance, the dummy variable $S B \_T O O L O W$ is set to be equal to 1 if the current level of benefits is deemed too low, and equal to zero otherwise. The reference category is $S B \_R I G H T$, indicating that the respondent deemed social benefits to have the right size. Since an attribute's marginal utility may vary with attitude, eg. (6) is modified to contain interaction terms involving the attitudinal variables, resulting in

$$
\begin{aligned}
\Delta V^{\prime}= & c_{0}^{\prime}+\cdots+\alpha_{1}^{\prime} S B_{-} T O O L O W+\ldots+\alpha_{2}^{\prime} \Delta R E D I S T+\alpha_{3}^{\prime} \Delta R E D I S T^{2}+\ldots \\
& +\lambda_{2}^{\prime} \Delta R E D I S T \cdot S B_{-} \text {TOOLOW }+\lambda_{3}^{\prime} \Delta R E D I S T^{2} \cdot S B_{-} T O O L O W+\ldots \\
& +\lambda_{4}^{\prime} \Delta R E D I S T \cdot S B_{-} \text {TOOHI }+\lambda_{5}^{\prime} \Delta R E D I S T^{2} \cdot S B_{-} T O O H I+\varphi^{\prime} .
\end{aligned}
$$

Table 12. Marginal WTP values for redistribution (in percent of monthly personal income and CHF) derived from the model extended to include ex-post evaluations of the current level of social benefits

\begin{tabular}{lcccl}
\hline Variable & Expected sign & MWTP, \% of income & MWTP, CHF & Std. error, CHF \\
\hline Social benefits too high (Group A) & - & -0.55946 & -26.75 & $16.70^{* * *}$ \\
The right amount (Group B) & $\approx 0$ & -0.41789 & -19.61 & $8.34^{* * *}$ \\
Social benefits too low (Group C) & + & 0.05487 & 2.47 & 8.09 \\
\hline
\end{tabular}

Note. $* * *$ denotes statistical significance of MWTP in $\%$ of income at the 1 percent level.

Hypothesis 1(A) of Section 3 states that demand for redistribution is expected to be negative if the currently provided level of social benefits is considered too high. It is confirmed, with MWTP for a one percentage point increase of the total amount of redistribution amounting to CHF -26.75 (see Table 12). Hypothesis 1(C), stating that the demand for redistribution should be positive if the level of social benefits is considered insufficient, finds some empirical support by a positive but insignificant MWTP of CHF 2.47. However, Hypothesis 1(B), predicting the demand for redistribution to be negative but close to zero for individuals who deem the current level of benefits just sufficient, cannot be confirmed. In fact, the average respondent in this group exhibits a significantly negative MWTP for redistribution of CHF -19.61 per month. A $t$ test indicates that the difference in MWTP values between respondent groups A and B is not significant, again contradicting Hypothesis 1(B).

As a check on the sustainability of the welfare state in the presence of preference heterogeneity, group-specific WTP functions are constructed. Group A is found to have their maximum WTP at a GDP share of 15.89 percent devoted to redistribution. The values of Groups B and C are 18.45 percent and 25.52 percent of GDP, respectively. Therefore, attitudes with regard to the amount of social benefits do go along with heterogeneous preferences with regard to income redistribution. These discrepancies point to sharp conflicts of interest in the 
event that the current amount of redistribution were to be reduced to 21 percent, the value preferred by the average citizen.

\subsubsection{Assessment of the Government's Role in Dealing with Inequality and Preferences for Redistribution}

Next, the simple model is extended by including the dummy variable GOV_REDUCE (=1 if the respondent thinks that the government should reduce the income gap between the rich and the poor, $=0$ otherwise) as well as its interactions with the attributes. Thus, eq. (6) is modified to read,

$$
\begin{gathered}
\Delta V^{\prime}=c_{0}^{\prime \prime}+\cdots+\alpha_{1}^{\prime \prime} G O V_{-} R E D U C E+\ldots+\alpha_{2}^{\prime \prime} \Delta R E D I S T+\alpha_{3}^{\prime \prime} \Delta R E D I S T^{2}+\ldots \\
+\kappa_{2}^{\prime \prime} \triangle R E D I S T \cdot G O V_{-} R E D U C E+\kappa_{3}^{\prime \prime} \triangle R E D I S T^{2} \cdot G O V_{-} R E D U C E+\ldots+\varphi^{\prime \prime} .
\end{gathered}
$$

Table 13. Marginal WTP values for redistribution (in percent of monthly personal income and CHF) derived from the model extended to include the assessments whether the government should reduce the income gap between the rich and the poor

\begin{tabular}{lllll}
\hline Variable & Expected sign & MWTP, \% of income & MWTP, CHF & Standard error, CHF \\
\hline Should not reduce (Group a) & - & -0.34515 & -16.68 & $6.35^{* * *}$ \\
Should reduce (Group b) & + & -0.08417 & -3.63 & 9.25 \\
\hline
\end{tabular}

Note. $* * *$ denotes statistical significance of MWTP in $\%$ of income at the 1 percent level.

Hypothesis 2(a) states that demand for redistribution is expected to be negative if a respondent believes that the government should not reduce the income gap between the rich and the poor. It is confirmed because MWTP in Group (a) is CHF -16.68 and statistically significant. Hypothesis 2(b) with its prediction for MWTP to be positive if a respondent wants the government to reduce the income gap cannot be confirmed. If at all, MWTP is negative in Group (b) but lacks statistical significance. Thus, individuals who stated support for inequality reduction by the government seem to exhibit inconsistent behavior by having negative MWTP for this reduction. However, the framing of the question posed prior to the DCE, "Do you agree with the following statement: 'By increasing the income tax rates for rich families and financially supporting poor families, the government should try to reduce the income gap between the rich and the poor'?" does not evoke the trade-off between the reduction of the income gap and the respondent's own income. By way of contrast, the MWTP values come from the Discrete Choice Experiment (DCE), where the budget restriction is inevitably present. Addressing the sustainability issue once more, recall that the average respondent would prefer a share of GDP devoted to redistribution of 21 percent rather than the current value of 25 percent. The difference between these values is statistically significant. However, group-specific WTP functions indicate that optimal values of REDIST differ, with 19.21 percent of GDP for Group (a) and 24.09 percent for Group (b), respectively. Therefore, demand for income redistribution as measured by this DCE, while below the amount provided by the government, once more differs importantly between subpopulations, rendering a reform of the Swiss welfare state difficult.

\section{Discussion and Conclusion}

In this paper, a Discrete Choice experiment (DCE) performed in 2008 served to elicit citizens' willingness to pay (WTP) for income redistribution. The main advantage of a DCE in the present context is that it permits to explicitly impose the budget constraint through a price attribute, defined as the tax share of income used to finance income redistribution. Respondents are made to simultaneously choose the total 'size of the pie', i.e. the total amount of income redistribution as a share of GDP, and the 'slices of this pie' devoted to different types of recipients and uses for different levels of the personal income tax (see Appendix B).

Based on a simple model relating choices to the attributes of redistribution only, the average Swiss citizen would have to be paid a compensation of CHF 11.78 (some US\$ 9.40) per month ( 0.25 percent of monthly income) for an additional percentage point of GDP devoted to public redistribution. In addition, a very marked status quo bias would have to be overcome by payment of another 63 percent of monthly income.

The experiment also permits to test several hypotheses concerning the determinants of the demand for redistribution without any confounding supply-side influences. In particular, Hypothesis 1 states that it is negative (close to zero) among citizens who think that public welfare currently provided welfare is excessive (sufficient). An extended model that includes the pertinent attitudinal variable as a regressor yields confirming evidence for the 'excessive' category; however, the 'sufficient' category is also associated with a negative marginal willingness to pay (MWTP) value, contradicting the hypothesis. Hypothesis 2 predicts that citizens who do (not) want government to reduce the income gap between the rich and the poor exhibit positive (negative) 
MWTP for redistribution. Here, the extended version of the model supports the 'not' component of the hypothesis whereas those in favor of closing the gap fail to exhibit positive MWTP. The major finding of the paper, however, is that estimated average WTP is maximum at 21 percent of GDP devoted to redistribution, clearly below and statistically significantly different from the current value of 25 percent. Moreover, this value differs importantly depending on attitudes toward the desirable amount of redistribution and the government's role in dealing with inequality. Thus, there is reason for concern with regard to the sustainability of the Swiss welfare state in its present extent.

The analysis presented in this paper is subject to several limitations. First, several behavioral explanations of the demand for redistribution (risk aversion, other beliefs, religiosity) were not tested. However, recent research suggests that up to 90 percent of cross-country differences in public spending can be related to institutional and behavioral factors (see e.g. Alesina \& Glaeser, 2004; Akkoyunlu et al., 2009). Thus, future work should be devoted to find out whether these factors also influence stated WTP for redistribution. A first step in this direction has been undertaken by Neustadt (2011), linking MWTP for redistribution to religiosity. Furthermore, as suggested by recent contributions to the public choice literature, citizens' preferences can be importantly influenced by political institutions, in particular by party programs (see e.g. Schläpfer et al., 2007). Thus, future work should be devoted to a detailed analysis of political preferences in order to find out whether these factors also influence stated WTP for redistribution. This analysis would, however, require addressing the identification problem once again, since the supply of public redistribution is governed by political institutions.

Second, the status quo bias found in this paper calls for more detailed analysis. To the extent that it reflects risk aversion, it should induce demand for redistribution-contrary to the results presented here. One possible explanation of why it is so high may be the fact that some preferences are not fully formed prior to a choice experiment (see e.g. Stutzer et al., 2007). Another explanation may be redistribution illusion, i.e. the fact that some respondents fail to correctly perceive the actual status quo. Finally, the evidence only relates to a point of time in one country and thus may be subject to transitory shocks and country-specific influences. Still, by appealing to citizens' stated preferences, the present contribution does shed light on the question whether a welfare state laying claim to one quarter of the GDP is sustainable.

\section{Acknowledgements}

The authors gratefully acknowledge financial support from the Swiss National Science Foundation (SNF) under Project no. 100012-116398. They received helpful comments on a previous version of this paper from Martin Beckmann, Douglas Bernheim, Joan Costa-i-Font, Marc Fleurbaey, Mireia Jofre-Bonet, Erzo Luttmer, Reinhard Madlener, David Myatt, Erik Schokkaert, Amos Witztum, participants in the conference 'The 9th Journées Louis-André Gérard-Varet' (Marseille, France, June 2010), the Workshop on Behavioural Welfare Economics (Venice Summer Institute, Venice, Italy, July 2010), the Research Seminar at the Max Planck Institute for Research on Collective Goods (Bonn, Germany, March 2011), the 4th Annual LMBS Research Conference (London Metropolitan University, United Kingdom, June 2011), the Special Guest lecture at the University of Western Australia (Perth, Australia, November 2011), and the Economic Research Seminar at the RWTH University (Aachen, Germany, January 2012).

\section{References}

Akkoyunlu, S., Neustadt, I., \& Zweifel, P. (2009). Why Does the Amount of Income Redistribution Differ between United States and Europe? The Janus Face of Switzerland. SOI Working Paper No. 0810, University of Zurich, Socioeconomic Institute.

Alesina, A., \& Angeletos, G. M. (2005). Fairness and Redistribution. The American Economic Review, 95(4), 960-980. http://dx.doi.org/10.1257/0002828054825655

Alesina, A., \& Giuliano, P. (2009). Preferences for Redistribution. Working Paper. http://dx.doi.org/10.2139/ssrn.1333762

Alesina, A., \& Glaeser, E. (2004). Fighting Poverty in the US and Europe: A World of Difference. Oxford University Press. http://dx.doi.org/10.1093/0199267669.001.0001

Alesina, A., \& La Ferrara, E. (2005). Preferences for Redistribution in the Land of Opportunities. Journal of Public Economics, 89, 897-931. http://dx.doi.org/10.1016/j.jpubeco.2004.05.009

Alesina, A., \& Rodrik, D. (1994). Distributive Politics and Economic Growth. Quarterly Journal of Economics, 109(1), 465-490. http://dx.doi.org/10.2307/2118470

Andreoni, J., \& Miller, J. (2002). Giving According to GARP: An Experimental Test of the Consistency of 
Preferences for Altruism. Econometrica, 70(2), 737-752. http://dx.doi.org/10.1111/1468-0262.00302

Beck, J. H. (1994). An Experimental Test of Preferences for the Distribution of Income and Individual Risk Aversion. Eastern Economic Journal, 20(2), 131-145.

Benabou, R., \& Ok, E. (2001). Social Mobility and the Demand for Redistribution: The POUM Hypothesis. Quarterly Journal of Economics, 116(2), 447-487. http://dx.doi.org/10.1162/00335530151144078

Benabou, R., \& Tirole, J. (2006). Belief in a Just World and Redistributive Politics. Quarterly Journal of Economics, 121(2), 699-746. http://dx.doi.org/10.1162/qjec.2006.121.2.699

Ben-Akiva, M. E., \& Lerman, S. R. (1985). Discrete Choice Analysis. MIT Press.

Boeri, T., Boersch-Supan, A., \& Tabellini, G. (2002). Pension Reforms and the Opinions of European Citizens. The American Economic Review, 92(2), 396-401. http://dx.doi.org/10.1257/000282802320191688

Boeri, T., Boersch-Supan, A., Tabellini, G., Moene, K. O., \& Lockwood, B. (2001). Would You Like to Shrink the Welfare State? A Survey of European Citizens. Economic Policy, 16(32), 7-50. http://dx.doi.org/10.1111/1468-0327.00069

Borisova, E., Govorun, A., Ivanov, D., \& Levina, I. (2014). Who to Help? Trust and Preferences over Redistribution in Russia. Higher School of Economics Basic Research Program 67/EC/2014. http://dx.doi.org/10.2139/ssrn.2512794

Carlsson, F., \& Martinsson, P. (2003). Design Techniques for Stated Preference Methods in Health Economics. Health Economics, 12, 281-294. http://dx.doi.org/10.1002/hec.729

Checchi, D., \& Filippin, A. (2004). An Experimental Study of the POUM Hypothesis. Research on Economic Inequality, 11, 115-136. http://dx.doi.org/10.1016/S1049-2585(04)11006-5

Fehr, E., \& Schmidt, K. (1999). A Theory of Fairness, Competition and Cooperation. Quarterly Journal of Economics, 114, 817-868. http://dx.doi.org/10.1162/003355399556151

Fehr, E., \& Schmidt, K. (2006). Handbook on the Economics of Giving. The Economics of Fairness, Reciprocity and Altruism: Experimental Evidence. Altruism and Reciprocity, 1.

Fong, C. (2001). Social Preferences, Self-Interest, and the Demand for Redistribution. Journal of Public Economics, 82, 225-246. http://dx.doi.org/10.1016/S0047-2727(00)00141-9

Guillaud, E. (2008). Preferences for Redistribution: A European Comparative Analysis. Working Paper.

Hensher, D. A., Louviere, J. J., \& Swait, J. D. (1999). Combining Sources of Preference Data. Journal of Econometrics, 89(1-2), 197-221. http://dx.doi.org/10.1016/S0304-4076(98)00061-X

Hirschman, A., \& Rothschild, M. (1973). The Changing Tolerance of Income Inequality in the Course of Economic Development. Quarterly Journal of Economics, 87(4), 544-566. http://dx.doi.org/10.2307/1882024

Hole, A. R. (2007). A Comparison of Approaches to Estimating Confidence Intervals for Willingness to Pay Measures. Health Economics, 16, 827-840. http://dx.doi.org/10.1002/hec.1197

Kriesi, H., \& Trechsel, A. (2008). The Politics of Switzerland: Continuity and Change in a Consensus Democracy. Cambridge University Press. http://dx.doi.org/10.1017/cbo9780511790676

Kuhn, A. (2005). Subjective Evaluations of Wage Inequality and Preferences for Redistribution. Working Paper, University of Zurich.

Lancaster, K. (1971). Consumer Demand: A New Approach. Columbia University Press.

Lizzeri, A., \& Persico, N. (2001). The Provision of Public Goods under Alternative Electoral Incentives. The American Economic Review, 91(1), 225-239. http://dx.doi.org/10.1257/aer.91.1.225

Louviere, J. J., Hensher, D. A., \& Swait, J. D. (2000). Stated Choice Methods-Analysis and Application. Cambridge University Press. http://dx.doi.org/10.1017/CBO9780511753831

Louviere, J. J., Pihlens, D., \& Carson, R. (2011). Design of Discrete Choice Experiments: A Discussion of Issues That Matter in Future Applied Research. Journal of Choice Modelling, 4(1), 1-8. http://dx.doi.org/10.1016/S1755-5345(13)70016-2

Luce, D. (1959). Individual Choice Behavior. Wiley and Sons, New York.

Manski, C. F., \& Lerman, S. F. (1977). The Estimation of Choice Probabilities from Choice Based Samples. 
Econometrica, 45(8), 1977-1988. http://dx.doi.org/10.2307/1914121

McFadden, D. (1974). Conditional Logit Analysis of Quantitative Choice Behavior. In P. Zarembka (Ed.), Frontiers of Economics (pp. 105-142). New York: Academic Press.

McFadden, D. (1981). Econometric Models of Probabilistic Choice. In Ch. Manski \& D. McFadden (Eds.), Structural Analysis of Discrete Data with Econometric Applications (pp. 198-272). MIT Press.

McFadden, D. (2001). Economic Choices. The American Economic Review, 91(3), 351-378. http://dx.doi.org/10.1257/aer.91.3.351

Meltzer, A. H., \& Richard, S. F. (1981). A Rational Theory of the Size of Government. Journal of Political Economy, 89(5), 914-927. http://dx.doi.org/10.1086/261013

Merino-Castello, A. (2003). Eliciting Consumers' Preferences Using Stated Preference Discrete-Choice Models: Contingent Ranking versus Choice Experiment. University Pompeu Fabra Economics and Business Working Paper No. 705. http://dx.doi.org/10.2139/ssrn.562982

Milanovic, B. (2000). The Median-Voter Hypothesis, Income Inequality, and Income Redistribution: An Empirical Test with the Required Data. European Journal of Political Economy, 16(3), 367-410. http://dx.doi.org/10.1016/S0176-2680(00)00014-8

Milesi-Ferretti, G. M., Perotti, R., \& Rostagno, M. (2002). Electoral Systems and Public Spending. Quarterly Journal of Economics, 117, 609-657. http://dx.doi.org/10.1162/003355302753650346

Molnár, G., \& Kapitány, Z. (2006a). Mobility, Uncertainty and Subjective Well-Being in Hungary. Discussion Paper 2006/5, Institute of Economics, Hungarian Academy of Science.

Molnár, G., \& Kapitány, Z. (2006b). Uncertainty and the Demand for Redistribution. Discussion Paper 2006/8, Institute of Economics, Hungarian Academy of Science.

Neustadt, I. (2011). Do Religious Beliefs Explain Preferences for Income Redistribution? Experimental Evidence. CESifo Economic Studies, 57(4), 623-652. http://dx.doi.org/10.1093/cesifo/ifr002

Neustadt, I., \& Zweifel, P. (2009). Economic Well-Being, Social Mobility, and Preferences for Income Redistribution: Evidence from a Discrete Choice Experiment. SOI Working Paper 0909, University of Zurich, Socioeconomic Institute.

Neustadt, I., \& Zweifel, P. (2011). Income Redistribution: How Should the Pie be Divided? MPRA Paper 35427.

Perotti, R. (1996). Growth, Income Distribution and Democracy: What the Data Say. Journal of Economic Growth, 1(2), 149-188. http://dx.doi.org/10.1007/BF00138861

Persson, T., \& Tabellini, G. (1994). Is Inequality Harmful for Growth? The American Economic Review, 84(2), $600-621$

Persson, T., \& Tabellini, G. (2000). Political Economics: Explaining Economic Policy. MIT Press.

Persson, T., \& Tabellini, G. (2003). The Economic Effects of Constitutions. Munich Lectures in Economics, MIT Press.

Pfarr, C. (2013). Einkommen, Mobilität und individuelle Präferenzen für Umverteilung: Ein Discrete-Choice-Experiment. Mohr Siebeck, Tübingen.

Pfarr, C., Schmid, A., \& Morkbak, M. (2014). Identifying latent interest groups: An analysis of heterogeneous preferences for income redistribution. Working Paper.

Rainer, H., \& Siedler, T. (2008). Subjective Income and Employment Expectations and Preferences for Redistribution. Economics Letters, 99, 449-453. http://dx.doi.org/10.1016/j.econlet.2007.09.011

Ravallion, M., \& Lokshin, M. (2000). Who Wants to Redistribute? The Tunnel Effect in 1990s Russia. Journal of Public Economics, 76, 87-104. http://dx.doi.org/10.1016/S0047-2727(99)00064-X

Rawls, J. (1999). A Theory of Justice. Belknap Press of Harvard University Press.

Roberts, K. W. S. (1977). Voting over Income Tax Schedules. Journal of Public Economics, 8, 329-340. http://dx.doi.org/10.1016/0047-2727(77)90005-6

Rodriguez, F. C. (1999). Does Distributional Skewness Lead to Redistribution? Evidence from the United States. Economics and Politics, 11(2), 171-199. http://dx.doi.org/10.1111/1468-0343.00057

Romer, T. (1975). Individual Welfare, Majory Voting, and the Properties of a Linear Income Tax. Journal of 


\section{Public Economics, 4, 163-185. http://dx.doi.org/10.1016/0047-2727(75)90016-X}

Ryan, M. (2004). A Comparison on Stated Preference Methods for Estimating Monetary Values. Health Economics, 13(3), 291-296. http://dx.doi.org/10.1002/hec.818

Samuelson, P. A. (1938). A Note on the Pure Theory of Consumer's Behaviour. Economics, 5(17), 61-71. http://dx.doi.org/10.2307/2548836

Schläpfer, F., Schmitt, M., \& Roschewitz, A. (2007). Competitive Politics, Simplified Heuristics, and Preferences for Public Goods. SOI Working Paper No. 0712 University of Zurich, Socioeconomic Institute.

Stutzer, A., Goette, L., \& Zehnder, M. (2007). Active Decisions and Pro-Social Behavior. Working Paper No. 07-13, Federal Reserve Bank of Boston.

Telser, H. (2002). Nutzenmessung im Gesundheitswesen. Kovač, Hamburg.

\section{Appendix A}

\section{Random Utility Theory}

Individual $i$ values alternative $j$ according to the utility $V_{i j}$ attained, which is given by

$$
V_{i j}=v_{i}\left(a_{j}, p_{j}, y_{i}, s_{i}, \varepsilon_{i j}\right)
$$

Here, $v_{i}(\cdot)$ denotes $i$ 's indirect utility function, $a_{j}$, the amount of attributes associated with alternative $j$, and $p_{j}$, price. The individual's income and sociodemographic characteristics are symbolized by $y_{i}$ and $s_{i}$, respectively. Finally, $\varepsilon_{i j}$ denotes the error term, which is due to the fact that the experimenter will never observe all the arguments entering $v_{i}$, imparting a stochastic element to observed choices.

As usual, the utility function is additively split into a systematic component $w(\cdot)$ and a stochastic one,

$$
V_{i j}=w_{i}\left(a_{j}, p_{j}, y_{i}, s_{i}\right)+\varepsilon_{i j}
$$

A utility-maximizing individual $i$ will prefer alternative $j$ to alternative $l$ if and only if

$$
w_{i}\left(a_{l}, p_{l}, y_{i}, s_{i}\right)+\varepsilon_{i l} \leq w_{i}\left(a_{j}, p_{j}, y_{i}, s_{i}\right)+\varepsilon_{i j}
$$

Due to the presence of the stochastic term, only the probability $P_{i j}$ of individual $i$ choosing alternative $j$ rather than alternative $l$ can be estimated, with

$$
\begin{aligned}
P_{i j} & =\operatorname{Prob}\left[w_{i}\left(a_{l}, p_{l}, y_{i}, s_{i}\right)+\varepsilon_{i l} \leq w_{i}\left(a_{j}, p_{j}, y_{i}, s_{i}\right)+\varepsilon_{i j}\right] \\
& =\operatorname{Prob}\left[\varepsilon_{i l}-\varepsilon_{i j} \leq w_{i}\left(a_{j}, p_{j}, y_{i}, s_{i}\right)-w_{i}\left(a_{l}, p_{l}, y_{i}, s_{i}\right)\right] .
\end{aligned}
$$

Thus, the probability of choosing $j$ amounts to the probability of the systematic utility difference $w_{i}[j]-w_{i}[l]$ dominating the 'noise', $\varepsilon_{i l}-\varepsilon_{i j}$. The error terms $\left\{\varepsilon_{i l}, \varepsilon_{i j}\right\}$ can be assumed to be normally distributed with mean zero and variances $\sigma_{l}^{2}$ and $\sigma_{j}^{2}$ as well as covariance $\sigma_{l j}$. Under these assumptions, $\varphi_{i j}:=\varepsilon_{i l}-\varepsilon_{i j}$ is also normally distributed with mean zero and variance $\sigma^{2}:=\operatorname{Var}\left[\varphi_{i j}\right]=\sigma_{l}^{2}+\sigma_{j}^{2}-2 \sigma_{l j}$. Thus, equation (A.4) can be represented as

$$
P_{i j}=\Phi\left(\frac{w_{-} i\left(a_{-} j, p_{-} j, y \_i, s_{-} i\right)-w_{-} i\left(a_{-} l, p_{-} l, y_{\_}, i s_{-} i\right)}{\sigma}\right)
$$

where $\Phi(\cdot)$ denotes the cdf of a standard normal distribution. This model is known as the binary probit model (Ben-Akiva \& Lerman, 1985). Hensher et al. (1999) provide empirical evidence suggesting that a linear specification of the function $w(\cdot)$ leads to good predictions in its middle ranges.

The simple model (3) in the body of the paper can be extended by including various socioeconomic variables (e.g. income group, level of education, social mobility). These variables need to be interacted with the product attributes as well as with the constant, giving rise to the extended model specification which allows to check for preference heterogeneity and thus to test Hypotheses 1 and 2 of Section 6.2. By means of a $t$ test one can investigate whether the differences in marginal WTP values between different socioeconomic groups are statistically significant. The computation of the variance of the marginal WTP values is performed by the delta method (Hole, 2007). The estimate of the variance is given by

$$
\operatorname{Var}\left[-\frac{\hat{\beta}_{k}}{\hat{\beta}_{p}}\right]=\left[\frac{\partial\left(-\frac{\widehat{\beta}_{k}}{\hat{\beta}_{p}}\right)}{\partial \hat{\beta}_{k}}\right]^{2} \operatorname{Var}\left[\hat{\beta}_{k}\right]+\left[\frac{\partial\left(-\frac{\widehat{\beta}_{k}}{\hat{\beta}_{p}}\right)}{\partial \hat{\beta}_{p}}\right]^{2} \operatorname{Var}\left[\hat{\beta}_{p}\right]-2 \frac{\partial\left(-\frac{\widehat{\beta}_{k}}{\hat{\beta}_{p}}\right)}{\partial \hat{\beta}_{k}} \frac{\partial\left(-\frac{\hat{\beta}_{k}}{\hat{\beta}_{p}}\right)}{\partial \hat{\beta}_{p}} \operatorname{Cov}\left[\hat{\beta}_{k}, \hat{\beta}_{p}\right]
$$




$$
=\frac{1}{\hat{\beta}_{p}^{2}} \operatorname{Var}\left[\hat{\beta}_{k}\right]+\frac{\hat{\beta}_{k}^{2}}{\hat{\beta}_{p}^{4}} \operatorname{Var}\left[\hat{\beta}_{p}\right]+2 \frac{\hat{\beta}_{k}}{\hat{\beta}_{p}^{3}} \operatorname{Cov}\left[\hat{\beta}_{k}, \hat{\beta}_{p}\right]
$$

The confidence interval can thus be created as follows,

$$
-\frac{\widehat{\beta}_{k}}{\widehat{\beta}_{p}} \pm z_{\alpha / 2} \sqrt{\operatorname{Var}\left(-\frac{\widehat{\beta}_{k}}{\widehat{\beta}_{p}}\right)}
$$

\section{Appendix B}

Status Quo and Selected Alternatives

Exhibit B1: Status Quo Card (current state of redistribution)

Tax Rate

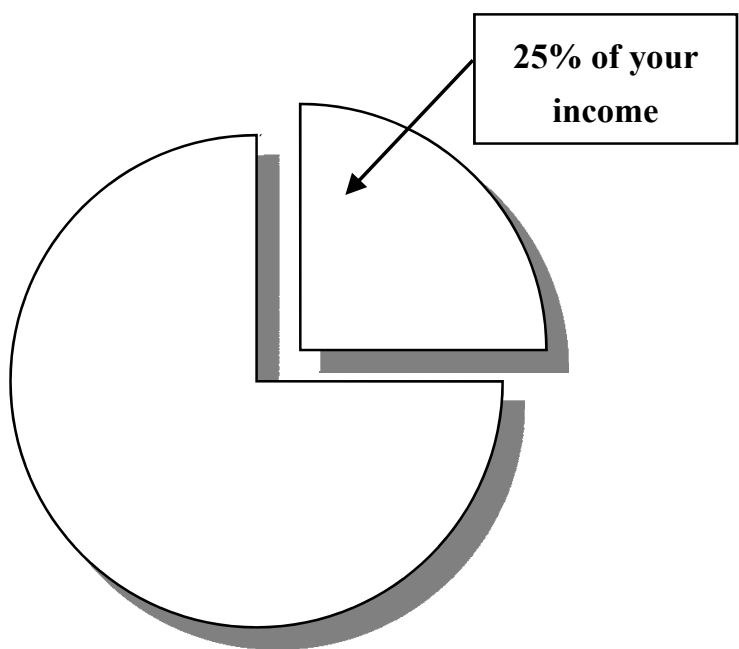

Use of Redistribution

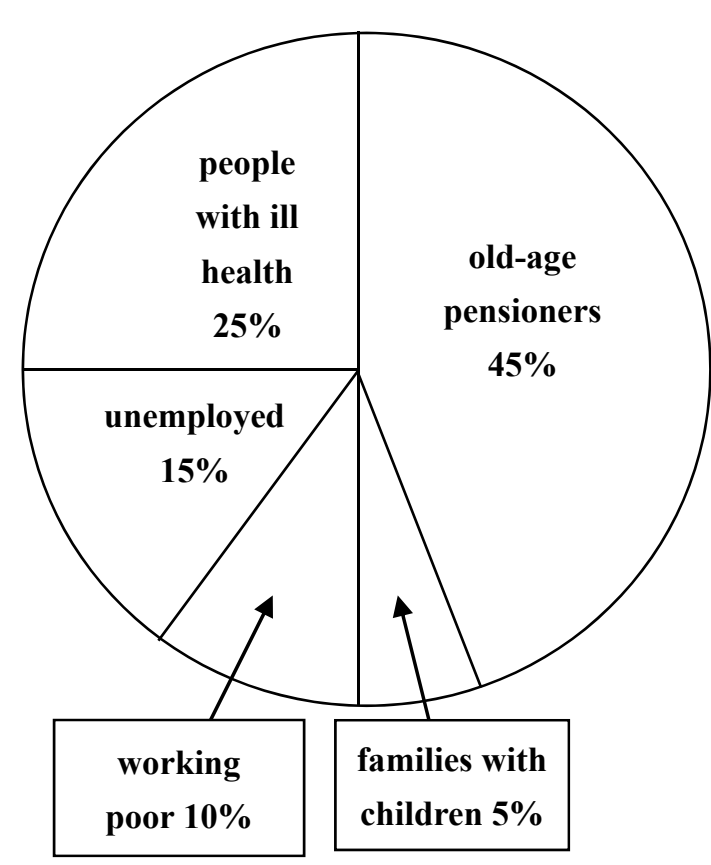

Amount of Redistribution

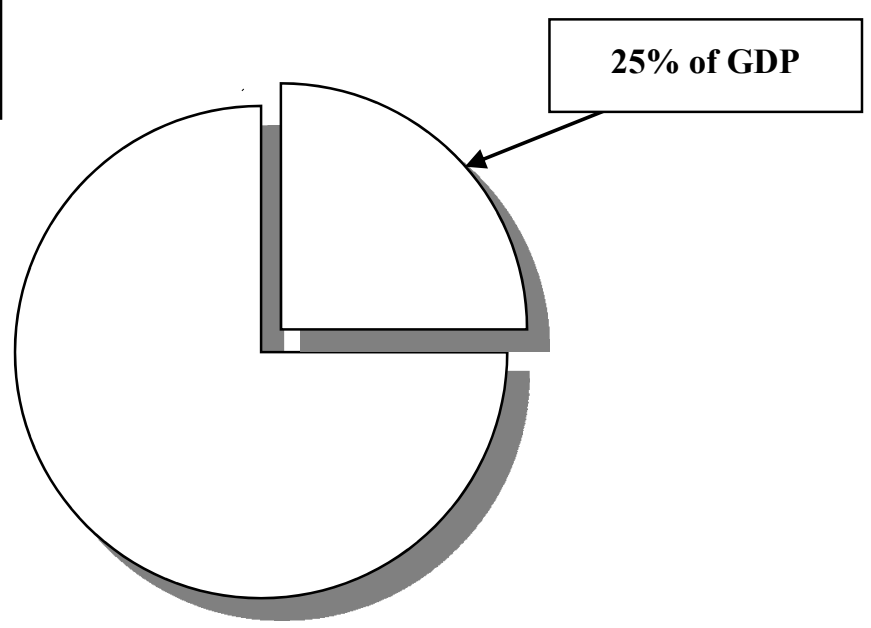

Nationality of Beneficiaries

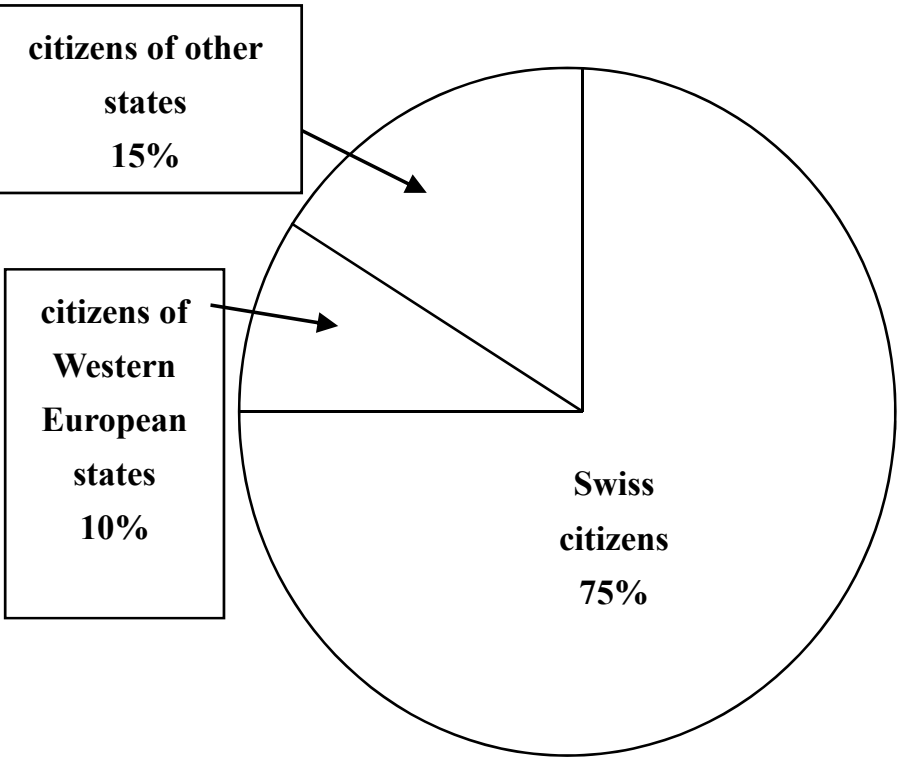


Exhibit B2: Card for Alternative No. 1

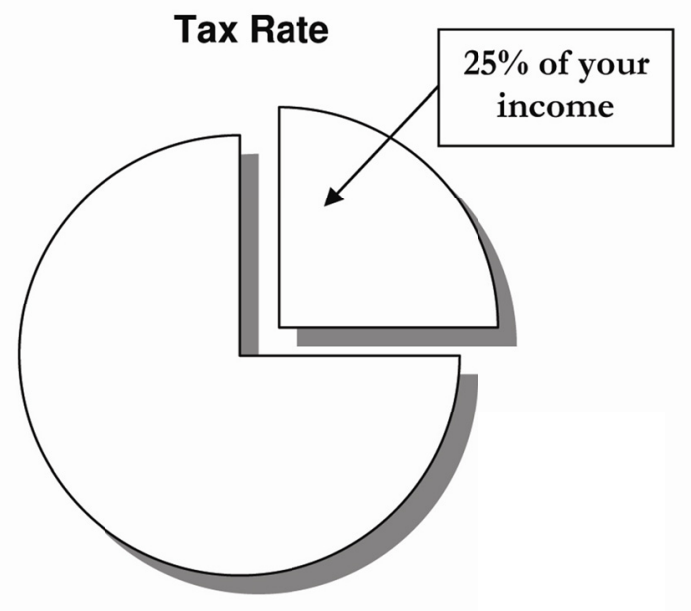

Uses of Redistribution

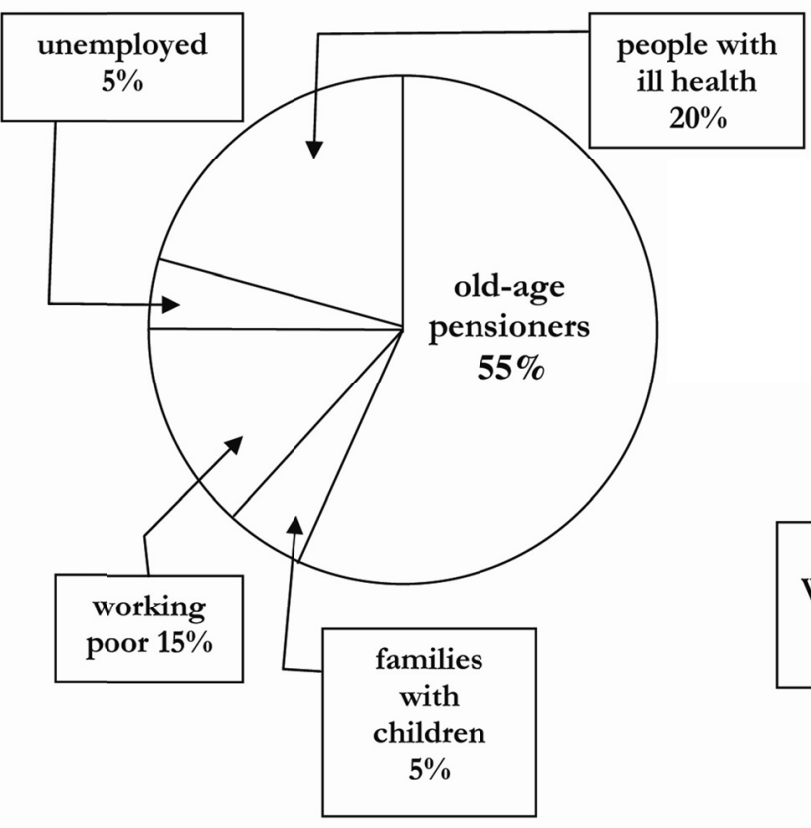

Amount of Redistribution

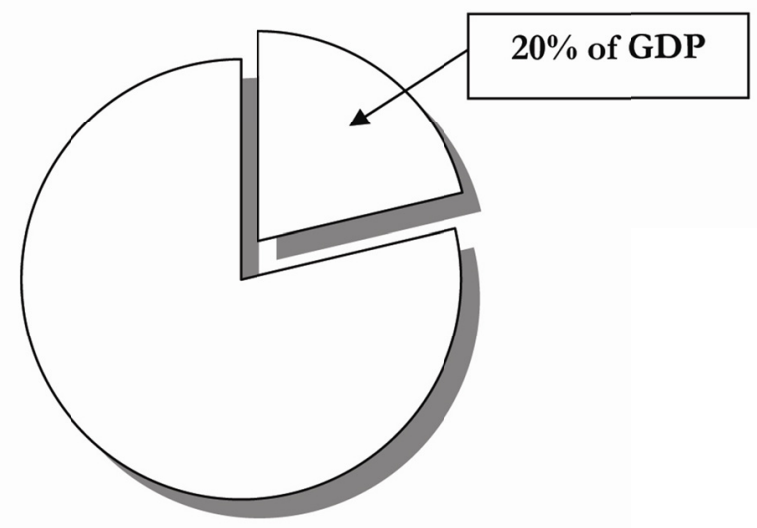

Nationality of Beneficiaries

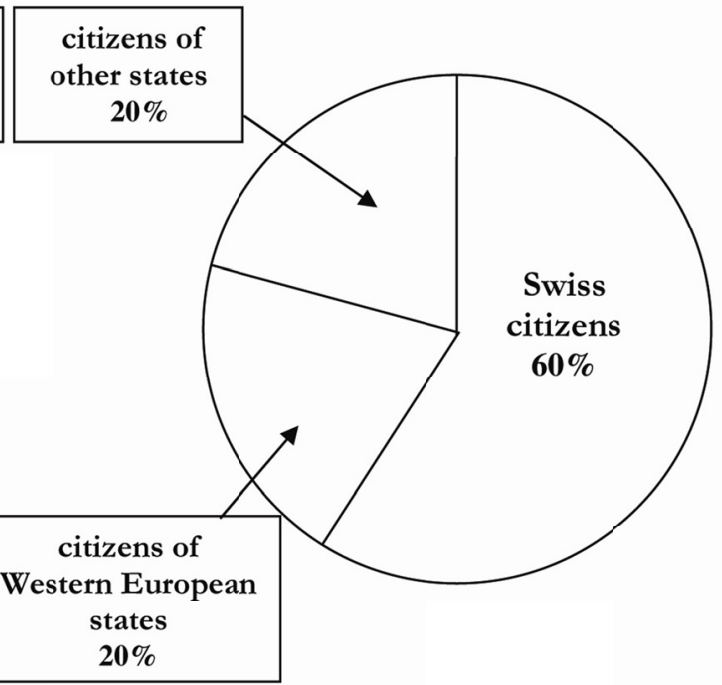




\section{Exhibit B3: Card for Alternative No. 2}

Tax Rate

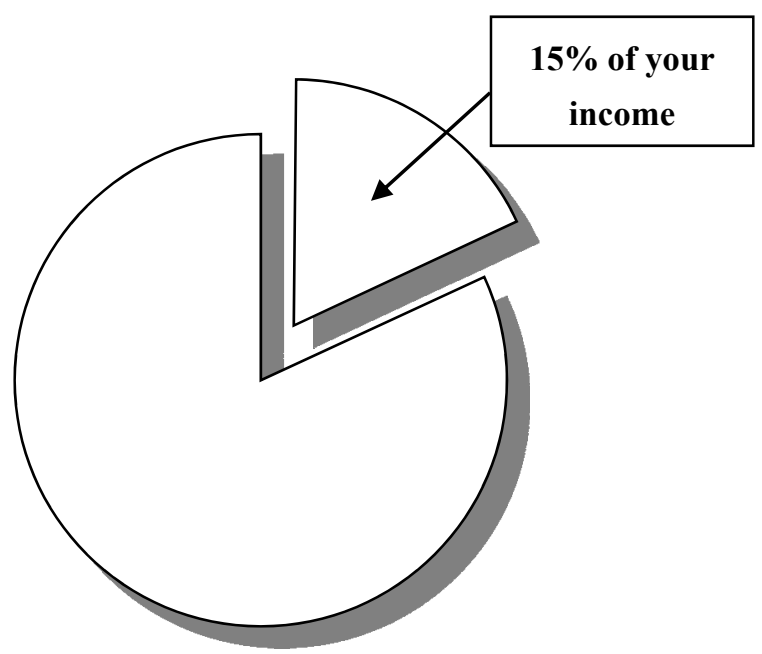

Uses of Redistribution

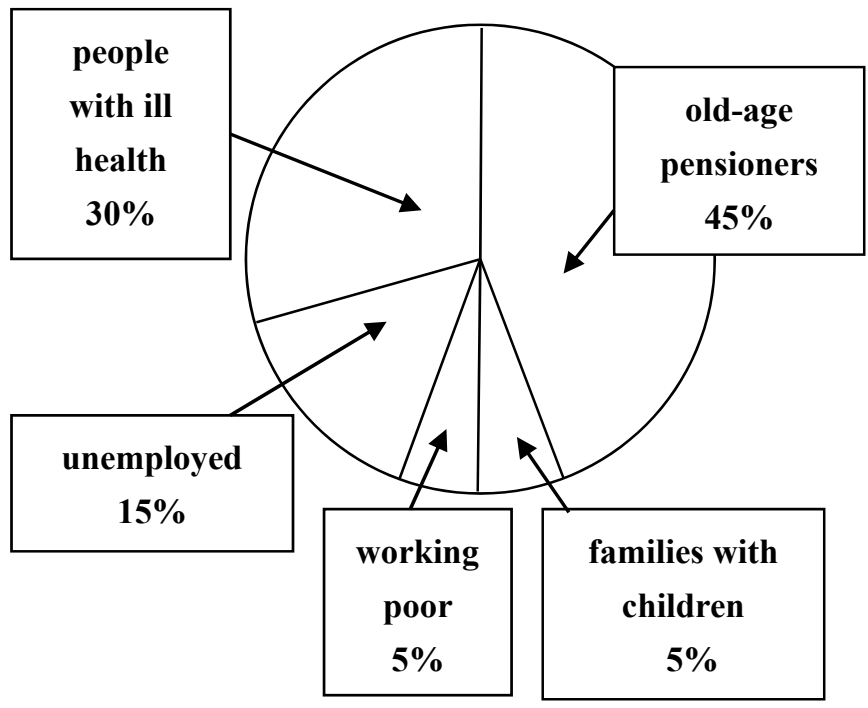

Amount of Redistribution

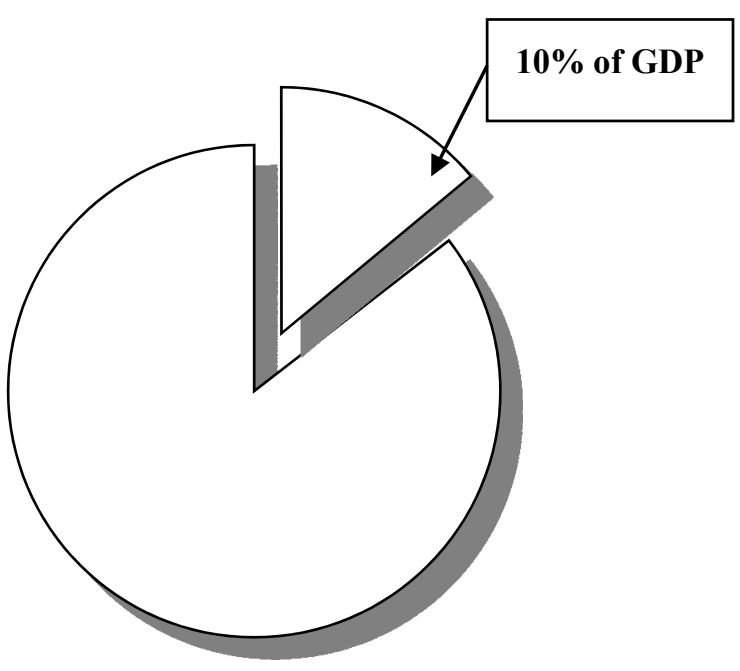

Nationality of Beneficiaries

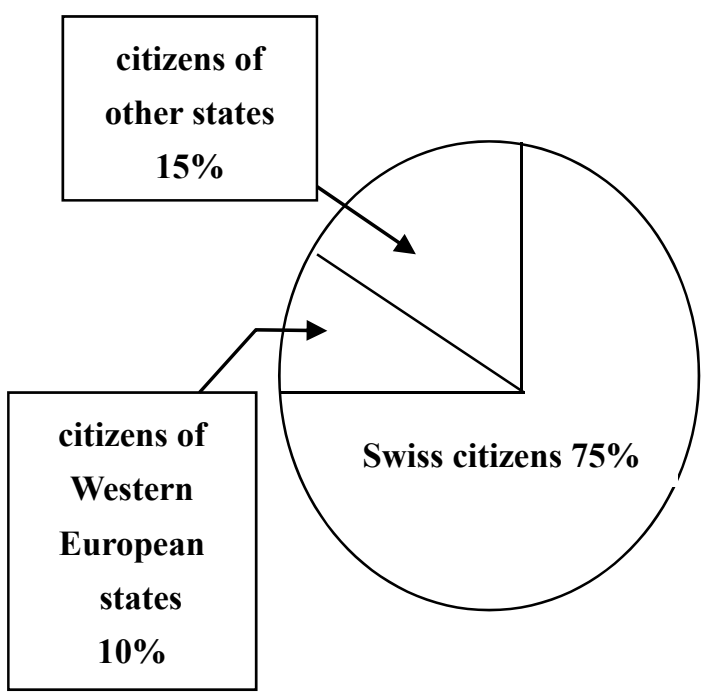

\section{Notes}

Note 1. Boeri et al. (2001) study international attitudes towards redistribution with a focus on pension and unemployment schemes in France, Germany, Italy, and Spain. They also perform CV experiments that impose an explicit trade-off between income and social insurance coverage on respondents, finding that people oppose an extension of the welfare state, with conflicts between young and old, rich and poor, and insiders and outsiders creating significant hurdles to welfare reform.

Note 2. The median voter's income is assumed to be below the mean. This assumption is satisfied for most economies.

Note 3. The 'tunnel effect' also works in the opposite direction, causing forward-looking agents with high incomes but downward mobility expectations to be in favor of redistribution. This prediction is confirmed by Ravallion \& Lokshin (2000) using a data set from Russia. Furthermore, Molnár \& Kapitány (2006a, 2006b) 
show that individuals who lack clear expectations about their future income favor redistribution even more than those with negative but clear expectations.

Note 4. The Rawlsian maximin rule uses the maximum improvement of the individual with minimum initial wealth as the sole criterion.

Note 5. By Roy's Identity, $x_{i j}=-\frac{\partial v(\cdot) / \partial p_{j}}{\partial v(\cdot) / \partial y_{i}}$, the (uncompensated) demand of individual $i$ for commodity $j$ corresponds to the negative ratio of partial derivatives of the indirect utility function with respect to price $p_{j}$ and income $y_{i}$. If one alternative is chosen, then the optimal quantity demanded is equal to one, i.e. $x_{i j}=1$. Therefore, Roy's Identity yields $\frac{\partial v}{\partial y_{i}}=-\frac{\partial v}{\partial p_{j}}$, i.e. the marginal utility of income is equal to the negative derivative of the indirect utility function with respect to price.

Note 6. For a recent discussion of alternative optimal designs in choice experiments, see Louviere et al. (2011).

\section{Copyrights}

Copyright for this article is retained by the author(s), with first publication rights granted to the journal.

This is an open-access article distributed under the terms and conditions of the Creative Commons Attribution license (http://creativecommons.org/licenses/by/3.0/). 